\title{
Food Lessons.
}

IDA S. Ilamkington, Dinector of Home Ecoxomes ron State of IRTODE ISLIND.

Snecess in the Food Conservation campaign depends on wider cooperation than we have yet brought abont. The housewives alone cannot solve the problen. 'They must culist the services of the men, the boys and girls; and most of all the children. Children are, of all people, the cassiest to interest. All it needs is to let them have a finger in the pic. One of the problems we are trying to work out is the making of acceptable war breals, and, having made them, to enlist the willingness of our honsehold to eat the product. No surer way of capturing the children's interest can be found than to let them make a loaf of war bread, nor does this require domestic science equipment. 'The teacher and her class may find inspiration in making an imaginary loaf.

First explain to the children that bread making is really gardenjng on a very small scale. We sow a crop, the yeast plant, in a ficld (the dough) which must funish all the essentinls for growth, that is warmth, moisture, air, lood, and room. to grow. The yeast cake, which is to make our crop, is composed of a large number of very tiny plants all crowled together and having been put to sleep by taking from them all, or nearly all, of their required moisture. 'Two things are needed hefore they ean work their magic. First they must be separated, like children in a school room. The little plants will not do good work when their heads are crowded close together. Such a grouj menus mischief, not work, as every teacher knows. Text they must have water added to them. A very good illustration, if not a strictly scientific one, is to show a box of Japanese water flowers crowded together and inert and put some of them into a glass of water, showing how they expand and move apart. The next illustration is to bring out how greatly flours differ in giving the yeast plant room to grow. Tave the children take a half a cup each of flour or five different kinds of flour and mix each into a little ball of dough. I'ut these into squares of cheesecloth and wash them in bowls of water until the starch part

1GIven before R. I. Science Teachers' Assoclation, Jan, 12, 1918. 
of the flour has been washed out. What remains in the cheesecloth will be that rubbery, stretchy substance which we call gluten and which is needed to nuake dough elastic. 'The next illustration shows how, under good conditions, the yeast plant actually does its work. Make a small lump of dough, using alout a cup of flour and 1/4 cup of lukewarm water in which a cake of yeast has been dissolved. Knead the little ball of dough until it is smooth and clastic. Then put it into a pint of water as warm as the hand can bear. It will sink to the bottom and show no signs of life, but as we wateh it, it will gradually begin to rise in the water and in about fifteen minutes will float on the surface, a light, spongy mass, somewhat resembling a jelly fish. Having actually seen the magic "work while you watch" the process of bread making will become one of vital interest to children. It will lead naturally to their preparing first samples of dough and afterwards rolls and bread at home and bringing them in to be judged by a jury of pupils. No child who has made war bread for a competition and taken a prize will refuse to eat the prize prodict. Wheatless days will have no further terrors for that child.

It has often been demonstrated in other lines of work how helpful the making of exhibits is in arousing the pupils' interest. Witness the exhibits shown here today which could not have been what they are had they not been prepared with whole-hearted interest.

Finally there is a strong dramatic instinct in children which may be counted on to develop their interest in food conseryation as it has done in other topics. A very successful production of a Hoover play entitled "Uncle Sam's Visit to Rhode Island" was giverby the Sunday School of the Cranston Street Baptist Church recently. It brought out how small is the number of things which we are asked to save and how large the number of possible substitutes. The boy who represented. White Bread was quite lost sight of by the time the various War Breads had appeared on the stage. The child who impersonated the Butter Ball sank into insignificance before the charms of Miss Beef Drippins who was adorned with a helmet promoted from the ranks of saucepans, and from which dangled streamers to simulate streams of fit.

The lesson of purpose and patriotism was driven home by the fact that no character approached Uncle Sam without saluting him and the flag. At the end of the performance the audience as 
a whole gave the salute and joined in the singing of America. While a performance like the above would require large numbers and more preparation than could be furnished in the average school, there is no lack of simple dialogues which could be used: The one appended, "Food Army Recruits", written by Miss Frances E. Saville, could be given with a minimum of preparatory work. The article entitled "The Home Guard"' in the December number of the Home Economies Journal could be most successfully adapted to dialogue form. Anything that proves to children that they are important factors in the national work we have undertaken means surer cooperation now and better citizenship in the days to come.

\section{Food Army Recruits.}

By Frances H. SAJilie.

Scene: Family Dining Room.

Bob. (Reading paper). "Another slacker caught at Glendale" (looking up) Say Jack, wouldn't you hate to be a slacker?

Jess. You needn't say anything, Bob Manning, you are a slacker and so is Jack.

Both. . What!

Jess. Yes; you are slackers.

Jack: How are we slackers? We have not been called to be soldiers and if we were called you bet we'd go, wouldn't we, Bob?

Bob. You bet we'd go. I wish I was old enough to go right now.

Jess. Well, Miss Judson says we must all be soldiers and that is why I called you slackers for you are not answering to the call to be the kind of soldiers she told us about in school today.

Bob. What kind of a soldier is that, sis?

Jess. A soldier in the food army. Didn't Mr. Smith tell you about it in your room today?

Jack. Yes, he did tell us something about it but I didn't pay much attention.

- Prue. (much younger) Miss Haley told us about it today, too. She said we could all join the Food Army and in arithmetic we counted up in our lesson how many pounds of sugar would be 